\title{
Exploring variation in reading comprehension among young adult Spanish-English bilinguals: The role of environmental language contact and attitudes toward reading.
}

Sara Ashley Smith,

California State University East Bay, US

Jessica G. Briggs,

University of Oxford, UK

Holly Pothier,

California State University East Bay, US

Sara Smith, Department of Human Development, California State University East Bay, 3087 Meiklejohn Hall, 25800 Carlos Bee Blvd, Hayward, CA, 94542, USA.

Email: sara.smith@csueastbay.edu

\begin{abstract}
Aims: The goal of this study was to investigate diversity among Spanish-English bilingual university-level students' reading outcomes and the impact of reading attitudes, motivation, and variation in language environment.

Design: The current study included 50 Spanish-English bilingual undergraduate students, mean age 21.8 years, from a university in the western United States. Participants were administered a battery of standardized assessments including measures of executive function, English reading comprehension, working memory, non-verbal IQ, and questionnaires addressing language environment, language behaviour and attitudes toward reading in English and Spanish.

Data and analysis: Hierarchical linear regression models regressing reading performance on questionnaire responses were performed.

Findings: Spanish-English bilingual university students showed differential reading comprehension outcomes, which were significantly predicted by differences in attitudes toward reading, extrinsic and/or instrumental motivation, and environmental language usage. A combined model of IQ, working memory, perceived English reading skills, and composite of positive attitudes toward reading in Spanish and English accounted for the most variance in reading comprehension scores, 38.5\%, $F(2,502), p=.03$. Greater
\end{abstract}


Spanish use for workplace customer communication significantly predicted higher English reading comprehension.

Originality: Distinct from previous research, learners' perceived value of Spanish reading and use of Spanish in the workplace accounted for variance in English reading outcomes.

Significance: Our findings that individual and environmental factors influence variation in reading outcomes indicates further heterogeneity among Spanish-English bilingual university students, with potential implications for reading development and university success.

Keywords: Spanish-English bilinguals, reading, reading attitudes, language environment, young adults. 


\section{Introduction}

Significant research has focused on comparing language and reading development among monolingual and bilingual learners, but gaps remain in our knowledge of diversity between bilinguals (Bialystok, Craik, \& Luk, 2008; Bialystok, Luk, Peets, \& Yang, 2010; Anderson, Vanderhoff, \& Donovick, 2013; Ransdell, 2003). Among second language learners in university settings, reading outcomes are impacted by reading attitudes and motivation (Briggs \& Walter, 2016). This may also be the case among bilingual university-level students. However, bilinguals experience language in varied environments, and variations in language contact are shown to contribute to differences in bilingual heterogeneity (Briggs, 2015b; Leon-Guerrero, Smith, Luk, 2016; Luk \& Bialystok 2013). In order to begin to build a more comprehensive understanding of heterogeneity among bilingual learners, we explored the relationship between language environment, attitudes, and reading comprehension among Spanish-English bilingual young adults, while controlling for cognitive factors known to influence reading (executive function, non-verbal IQ, working memory), using a battery of standardized assessments for reading, problem-solving working memory and executive function, and background questionnaires addressing language environment, language use, reading behaviours and attitudes among US Spanish-English bilinguals. Additionally, we seek to further refine theoretical frameworks regarding relationships between attitudes and motivation and linguistic achievement in bilingual contexts. 


\section{Spanish-Bilinguals in the US Educational Context}

Spanish-English bilinguals in the United States (US) have been the focus of a great deal of research during early and middle childhood. However, less attention has been paid to development during later years and there is a dearth of research on diversity between college student US Spanish-English bilinguals. This group of learners represents a significant population of children in the US, likely increasing in the future as the population ages and overall population numbers increase. The number and percentage of Latino students attending college in the United States has grown in recent years; the percentage of enrolled college students who identified as Latino increased from 9.9\% in 2000 to 15.8\% in 2013 (3,091,100 individuals; US Department of Education, 2014). Additionally, the percentage of Latino individuals attending college between the ages of 18-24 increased from 21.7\% in 2000 to 33.8\% in 2013 (US Census Bureau, 2014). Roughly one quarter of Latinos are English-speaking monolinguals while 38\% are monolingual Spanish speakers. Approximately a third (36\%) of Latinos in the US are bilingual in Spanish and English. From these data, we assume that, of US Latinos who speak English, roughly 59\% of are bilingual (Pew Research Center, 2013); accordingly, as much as 59\% of Latino college students in the US (who by definition speak English at the college entrance level), or 1.823 million students (utilizing the Dept. of Education info above) are bilingual, to some degree, in Spanish and English.

Much childhood research emphasizes whether or not bilingual Spanish-English students acquire "college level English”, which is usually defined as being able to pass standardized entry examinations and completing English language high school with a satisfactorily high GPA depending on accepting institution; college students should have 
by definition met this threshold. However, these learners are still developing language in particular, reading and writing skills. Additionally, college students are not homogeneous. While all have met the reading level required for college entry, variation remains between bilingual college students; students have different study habits, programs of study, behaviour, and attitudes. Though students may have met minimum threshold for college entry, they are no more finished developing reading skills than are monolingual college students or college students with English as a second language.

\section{Bilingualism and Within-Population Differences in Reading Attainment}

Contributing to within-population differences among bilingual college students, and bilingual populations in general, are factors such as varying levels of language proficiency (both empirically measured and self-reported) and daily language usage, which have been shown to impact heterogeneity in language skills, even among bilinguals with similar age of bilingual onset (Fishman \& Cooper, 1969; Luk \& Bialystok, 2013). An increasing body of evidence suggests that bilingual language processing effects are bidirectional, even for those living in monolingual environments, with each language affecting the other; comprehension and production of both languages is impacted by proficiency levels of both, moderated by context and experience (see Kroll, Dussias, Bogulski, \& Valdes Kroff, 2012 for a review). Differing bilingual experiences including daily usage, language environment, proficiency, and the interaction between proficiency level and usage, all exert influence on language and cognitive outcomes for bilinguals (Kroll et al., 2012). Previous work among Spanish-English bilinguals specifically has demonstrated environmental language usage and self-reported proficiency to have significant relationships with language outcomes. Fishman and 
Cooper (1969) found that self-reported proficiency in both English and Spanish, and English language usage were the best predictors of linguistic ratings for Spanish-English bilinguals living in a majority English context. Dussias and Sagarra (2007) found that Spanish-English bilinguals applied sentence parsing strategies consistent with their second language (English) when reading Spanish sentences only after having been immersed in an English environment for an extended period of time, indicating daily language usage in one language exerted an influence on reading in the other. The bilingual dual language system is dynamic and adaptive, impacted by environment and usage (Kroll et al., 2012). As such, multi-dimensional measurement that captures diversity in proficiency, environment and usage is necessary for researching withinpopulation differences among bilinguals (Luk \& Bialystok, 2013). Daily language use and self-reported proficiency in both English and Spanish are therefore likely to have a significant relationship with English reading outcomes among Spanish-English bilingual university students.

Bilingualism more broadly has been linked to both advantages and disadvantages in language and cognition. Previous researchers have found evidence that bilingualism may confer certain benefits to executive function (also known as cognitive control), both among adults (see Kroll \& Bialystok, 2013 for a review) and children (see Akhtar \& Menjivar, 2012; Barac, Bialystok, Castro \& Sanchez, 2014; Kapa \& Colombo, 2013 for reviews). However, other research suggests that it can also be associated with constricted lexical access and limited vocabulary (Bialystok, Craik, \& Luk, 2008; Bialystok, Luk, Peets, \& Yang, 2010; Anderson, Vanderhoff, \& Donovick, 2013). Ransdell (2003) found that bilingual Spanish-English college students, when matched with monolingual peers 
on grammatical awareness, phonological awareness, expressive vocabulary, vocabulary density, and writing quality, showed lower performance in receptive vocabulary, reading comprehension, and writing fluency relative to monolinguals. Because reading comprehension is mediated, in part, by the use of reading strategies (Afflerbach, Pearson, \& Paris, 2008), demonstrated variation in strategy use across linguistic groups and levels of ability (Anastasiou \& Griva, 2009; Lau 2006) may be responsible in part for this difference. Research focused specifically on Spanish-English bilingual college students suggests that prior knowledge and context strategies are the methods most commonly used (Quiroz, 2014); this study differentiated between methods most used by "good” Spanish bilingual readers (scoring above $80^{\text {th }}$ percentile on a standardized reading test) from those used by “average” readers (between $50^{\text {th }}$ and $70^{\text {th }}$ percentile), finding that while the "good" readers used more cognate-based strategies, focusing on words with shared linguistic roots in both languages, the "average” readers employed more context strategies, using context for meaning and comprehension support.

Non-linguistic cognitive factors have also been shown to predict reading comprehension, in particular executive function (EF), non-verbal IQ, and working memory (Engle, Cantor, Carullo, 1992; McVay \& Kane, 2012; Sesma, Mahone, Levine, Eason \& Cutting, 2009). Research on deficits in these areas and reading disability indicates successful reading comprehension necessitates use of these underlying cognitive skills, thus their strong covariation among typical readers (Engle et. al.,1992; Sesma et. al., 1999). Because these normal, individual differences impact variation in reading comprehension, the current study controlled for these factors in order to specifically identify non-cognitive within-population differences. 


\section{Psychosocial Perspectives on Bilingual Attainment}

The psychosocial standpoint of a language user/learner is a crucial factor in his/her linguistic achievement, particularly for bilinguals who are obliged (to a lesser or greater extent) to achieve competence in the majority language (Appel \& Muysken, 2005). A number of theoretical frameworks have been suggested to account for psychosocial factors (such as attitudes, motivations and beliefs) that are applicable to language learning contexts. For example, Eccles et al.’s (1983) Expectancy-Value Theory posits four components to attitudinal standpoint: (1) Interest-Enjoyment value, denoting personal interest in a given task or activity; (2) Attainment value, indicating the personal significance of a given task or activity to an individual's self-image and/or goals; (3) Utility value, referring to the usefulness of a given task/activity to an individual achieving his/her goals; and (4) Cost value, denoting the extent to which a task/activity incurs a temporal or emotional cost. This model is based on the premise that achievement is engendered from two constructs: (1) the level of expectancy for success in a given task/activity, which is derived from task-specific self concept and perceptions of task difficulty; and (2) the value an individual places on succeeding in that task/activity. These two constructs bear strong links to Deci and Ryan’s (1985) Self-Determination Theory, which postulates two facets of motivation: (1) Intrinsic motivation, referring to engaging in a task for its own sake (i.e. out of interest or enjoyment; allied to Expectancy); and (2) Extrinsic motivation (also termed Instrumental motivation by Gardner, 1972), denoting engagement in a task to achieve a separable, external goal (allied to Value). In contrast to the construct of Instrumental motivation, Gardner and Lambert (1979) proposed 
Integrative motivation as a concept, comprised of both attitudes and motivation and denoting positivity toward the target language group and integration into that group.

\section{Evidence of Psychosocial Effects}

There is a wealth of empirical evidence to support the relationship between attitudes and motivation and linguistic achievement in bilingual contexts. For example, Gardner et al. (1976) found that both Integrative and Instrumental factors significantly predicted the achievement in French of English-speaking Canadians. Likewise, Masgoret \& Gardner’s (2003) meta-analysis found a strong association between attitudes and motivation and L2 achievement. The literature also points to a significant positive relationship between attitudes and motivation toward reading in an L2 and academic achievement. For example, Özönder’s (2015) study of tertiary-level L2 learners of English in Turkey found that L2 reading attitudes and motivation, as measured by the Foreign Language Reading Attitudes and Motivation Scale (FLRAMS; Erten et al., 2010), significantly correlated with participants’ GPAs, with a direct, positive relationship between academic achievement and attitudes toward the intrinsic value of reading.

Most crucially to the present study, there is also a strong body of evidence in favour of a robust relationship between attitudes and motivation and reading achievement specifically. For example, Petscher’s (2010) meta-analysis of first language reading at school level found that reading achievement is strongly related to reading-related attitudes, as did Briggs and Walter's (2016) meta-analysis of extensive second language (L2) reading and the motivation and attitudes toward L2 reading of young language learners (11-18 years old). Netten, Droop and Verhoeven (2011), in an investigation of 
the predictors of reading literacy for both first and second language school aged readers, found that motivation and attitudes related to self-perception were both predictive of reading attainment. Psychosocial factors have also been found to explain variance in reading comprehension in addition to that explained by variables pertaining to cognitive control and linguistic ability. For example, in a study of the relationship between reading self-concept (i.e. perceived ability and attitudes) and L1 reading comprehension, Katzir, Lesaux and Kim (2009) found that self-concept made a significant contribution to reading comprehension over and above that made by verbal ability and word and non-word reading.

Research into motivation/attitudes and L2 reading has further sought to define which facets of motivation and attitudinal beliefs are most predictive of attainment in reading. A preponderance of studies have found that Intrinsic motivation (i.e. engaging in a task for the sake of enjoyment and/or interest) is the motivational facet most positively correlated with reading achievement (Tercanlioglu, 2001; Dhanapala, 2006; Takase, 2007; Dhanapala \& Hirakawa, 2016), while others have found evidence to the contrary, indicating that Extrinsic (Instrumental) motivation is solely or more strongly predictive of reading ability (Kim, 2011; Lin, Wong, \& McBride-Chang, 2012). It is likely that this divergence of research findings with regard to psychosocial constructs and reading outcomes is in part derived from the variety of sociolinguistic contexts in which studies have been carried out. Motivation and attitudes towards learning and using a language are dynamic constructs that are dependent in part on the influence of the social setting(s) in which the language(s) are (or might be) used (as discussed below with reference to Bourdieu (1994/1998)). 


\section{The Role of Language Contact and Environment}

Evidence from the field of Second Language Acquisition (SLA) suggests that the amount and type of contact with a language that an individual experiences is likely to influence the individual's competence in using that language. For L2 learners the research indicates that there is a positive relationship between contact with the target language and a number of aspects of linguistic competence: oral fluency (Yager, 1998; Freed, Segalowitz \& Dewey, 2004; Segalowitz \& Freed, 2004; Hernández, 2010); lexical knowledge (Segalowitz \& Freed, 2004; Dewey, 2008); phonological control (Muñoz \& Llanes, 2014); and intercultural competence (Martinsen, 2011). The findings of these studies indicate that the more contact with the $\mathrm{L} 2$ in informal environments (i.e. outside of formal educational settings), the better, and that different types of informal L2 contact impact upon different facets of L2 competence. For example, the proportion of time spent interacting with 'native' L2 speakers has been found to correlate positively with gains in intercultural sensitivity (Martinsen, 2011) and degree of foreign accent (Muñoz \& Llanes, 2014). Linguistic gains deriving from language contact and use in informal environments may not only be due to increased and varied opportunities for input, negotiation for meaning, and output in the L2 (i.e. the interactionist perspective). Bourdieu's (1994/1998) Social Theory posits that individuals will invest in capital (such as competence in a second or additional language) according to the value of that capital to their social world. As such, language use in informal environments may not only retain and develop linguistic competence, but also in and of itself raise the value of bilingualism and linguistic competence as capital, particularly, one might argue, in environments where bilingualism accrues significant social returns, such as in a workplace that deals 
with clientele from more than one first language background. One consequence of a rise in the value of capital, according to Bourdieu (1994/1998), is a rise in investment (defined psychoanalytically as desire/motivation) in that capital, and there is a wealth of evidence of the positive relationship between motivation and linguistic achievement in SLA (as discussed above). Thus, increased contact with and use of a second language in informal environments is related to increased linguistic competence in and motivation toward using that language.

With regard to language contact/environment and reading specifically, a wealth of studies have established that amount of sustained exposure to print (termed "Extensive Reading”) in a first language is significantly positively correlated with reading ability (Stanovich, 2000; Krashen, 2004; Grabe, 2009; Mol \& Bus, 2011). This relationship is also borne out in L2 reading. For example, Pichette (2005) found that for college level French-speaking learners of English in Canada, L2 reading comprehension had a strong relationship ( $r=.35$ ) to amount of time spent reading in English. Hayashi’s (1999) study of Japanese college level students of English similarly found a strong positive effect of contact with L2 texts on reading ability and vocabulary knowledge. There is also research that indicates a relationship between bilinguals' reading competence and other types of language contact. For example, in the European context, German adolescents' high school attainment scores (compiled within PISA, 2009) revealed a strong negative association between reading literacy and not using the test language in the home environment (OECD, 2010).

Contact with linguistic environments that promote or facilitate codeswitching are likely to influence bilinguals' reading comprehension skills. The literature suggests a 
direct relationship between codeswitching and executive function; particularly, inhibitory control. For example, a positive effect of frequent codeswitching on task switching was found by Prior and Gollan (2011) and Yim and Bialystok (2012), and frequent codeswitching predicted smaller mixing costs in Soveri, Rodriguez-Fornells and Laine (2011). Given the link between non-linguistic cognitive factors (such as executive function) and reading comprehension among bilinguals, as discussed above, it is reasonable to expect that codeswitching may be related to reading performance in bilinguals. Indeed, some studies have demonstrated that linguistic environments in which codeswitching takes place have a positive effect on L2 reading comprehension. For example, for university level EFL learners in Iran, Yeganepoor and Seifoori (2016) found that a code-switching condition was related to increased reading comprehension achievement in L2 English.

\section{Research Aims}

Therefore, considered in sum, the findings of the research indicate that language contact and use outside of formal educational environments is highly likely either to facilitate or constrain the development of reading competence in language users and learners, and to impact on motivation and attitudes, which in turn themselves have an influence on linguistic attainment.

To shed further light on the relationship between language environment, attitudes, and English reading comprehension among Spanish-English bilingual young adults, the current study explores the following research questions: 1) Which variables best account for variance in reading comprehension scores among Spanish-English bilingual undergraduates? 2) Do any environmental factors uniquely contribute to variance in 
reading comprehension scores among Spanish-English bilingual undergraduates? 3) What is the attitudinal and behavioural reading profile of Spanish-English bilingual undergraduates?

\section{Method}

\section{Participants}

The current study included 50 Spanish-English bilingual undergraduate students aged between 18 and 30 years (mean age 21.8 years, standard deviation=2.47 years), 44 females and 6 males. Participants were recruited, via emails and physical posters, from a four-year public university on the west coast of the United States of America. All participants report learning Spanish from birth, and English before or at age 5. All participants report that they did not have a diagnosis of developmental or learning disability. All self-identified as Chicanx, Hispanic, or Latinx. Forty-eight were full-time students, 2 part-time students; 34 work part-time, 10 work full-time. Thirty-six report receiving government Pell Grants (government financial assistance for low-income students whose calculated expected financial contribution, a figure calculated using annual family income, falls significantly below cost of university attendance), 26 receive government student loans. All participants were schooled entirely in the United States, at state-funded (public) schools in the central/northern half of the state of California, in English; 14 report some exposure to Spanish in elementary and secondary school bilingual programs (mean amount of bilingual Spanish schooling $=0.54$ years, maximum of 2 years). Students came from a variety of majors including Liberal Studies, Health Sciences, Social Sciences, Business and Engineering. No participants majored in a foreign language or language arts. Participants report maternal educational backgrounds 
of: "Less than high school” $(n=25)$, "High school diploma or equivalency (GED)" ( $n=$ 16), “Associate degree (junior college)" ( $n=6)$, and "Bachelor’s degree” $(n=3)$.

\section{Procedures}

Participants were administered a battery of standardized assessments validated for use with US English speaking populations using Pearson Q-active tablet testing, including D-KEFS, Trails and Color-Word Inhibition subtest (executive function), WIAT III Reading Comprehension (English reading comprehension), WAIS IV Working Memory (WM) and Matrix Reasoning (non-verbal IQ); as well as two measures of language environment and language behaviour, an adapted version of Language and Social Background Questionnaire (LSBQ; Luk \& Bialystok, 2013) addressing language contact by type (Reading/Writing/Listening/Speaking) and environment (Home/School/Work), and a questionnaire regarding attitudes and motivations toward reading in English and Spanish.

All measures were administered via a two touch-screen tablet system; some assessments also required supplemental paper and pencil materials (D-KEFS, Trails and Color-Word Inhibition subtest). Testing battery was administered individually, in English, in the same order to all participants, by a trained tester. Testing sessions took place in a quiet, private room with minimal distractions. Test results were automatically scored and encrypted through the Pearson Q-interactive testing system and sent to an online, protected database. Results were then downloaded and transferred into IBM SPSS Statistics statistical analysis software package for analysis.

\section{D-KEFS, Trails and Color-Word Inhibition subtests (Delis, Kaplan, \&}

Kramer, 2001). The D-KEFS Trail-Making subtest is comprised of four connect-the- 
dots activities and a cancellation task (Conditions 1-5). Four of the conditions enable the investigator to establish normative data such as visual scanning, number sequencing, letter sequencing, and motor speed. The participant first completes the cancellation task (Condition 1), requiring them to visually scan a page of numbers and letters and mark each instance of a designated number or letter; any omission errors are recorded. The following two tasks, Conditions 2 and 3, entail connecting marked dots in alphabetical and numerical order, respectively. The operative task, Condition 4, requires the test taker to sequentially connect a series of points while switching between letters and numbers in order to test cognitive flexibility in visual-motor tasks. In Condition 5, participants quickly trace a dotted line connecting the points.

Designed to measure inhibition of the dominant and automatic response, D-KEFS Color-Word Inhibition subtest utilizes the Stroop effect (Stroop, 1935). The first two measures establish the basic ability to properly read from a list of written colours as well as visually identify a series of colours. The third task requires the participant to name the colour of the ink in which each word is printed; the ink colors are all incongruent to the corresponding written colour (e.g. the word 'red' printed in green ink). The participant must therefore inhibit the dominant response (to read the word rather than name the mismatched ink colour) in order to successfully complete this task. Combining inhibition and switching, the final task in this measure requires participants to switch between naming the ink colors and reading the written colors; this measures mental flexibility in addition to inhibition of the dominant response. Scores for both subtests are scaled at 10 .

WIAT III Reading Comprehension subtest (Wechsler, 2009). The Reading Comprehension section of the WIAT-III is a standardized, validated measure of 
participant ability to understand what he or she has read. Participants were instructed to read four passages (for example, informational passages, stories, letters of correspondence) presented on a tablet. Participants had an unlimited amount of time to read the passage to themselves, silently or aloud, and then were verbally asked factual and conceptual questions regarding passage content. A list of potential responses (correct and incorrect, including "I don’t know" and "Pass”) to the questions were presented to the tester, who selected from the list the answer that was given by the test taker, minimizing the need for tester judgement. If the test taker did not provide one of the given responses, the test taker was prompted to try to give another response, until one of the many response options on the list was given. In this study, none of the respondents provided an answer that was not listed in the potential responses (correct and incorrect). Readers were permitted to refer back to the passages while answering questions. Participants in the present study were presented with the 12th grade version of the subtest. Standardized scores were scaled at 100 , representing 50th percentile for individuals in the US at 12th grade reading level.

\section{WAIS IV, Working Memory and Matrix Reasoning subtests (Wechsler,}

2008). The Digit Span subtest in the Working Memory section measures working memory, auditory processing, and attention. For each item on this measure, the test administrator read a series of numbers aloud to the participant; participants were informed that the tester could not repeat the series a second time. For the first section of the digit span, participants were instructed to repeat the series back to the tester in the same order. For the second, participants were required to repeat the number series in 
reverse order. Finally, participants were asked to arrange the numbers in the series from least to greatest in the third section.

Matrix reasoning, a subtest in the Perceptual Reasoning section of the WAIS-IV, measures fluid intelligence, nonverbal abstract reasoning, and perceptual organization, collectively referred to as non-verbal IQ. Each item on this measure consisted of a sequence or pattern of images. Participants were instructed to indicate which image they thought logically completed the sequence or pattern. Scores for both subtests are scaled at 10.

\section{Language and Social Background Questionnaire (LSBQ; Luk \& Bialystok,}

2013). Participants were asked to complete a modified version of the LSBQ (Luk \& Bialystok, 2013). This questionnaire was developed specifically for bilingual populations to capture variation in language environment, proficiency, and usage among minority language speakers in a majority language environment. The LSBQ was designed to measure multiple related dimensions of bilingualism for assessing within-population difference and has been previously validated with 110 Canadian bilinguals, as well as used in subsequent studies addressing bilingual heterogeneity and cognitive consequences of bilingualism (Bialystok, Poarch, Luo \& Craik, 2014; Friesen, Latman, Calvo, \& Bialystok, 2015; Leon Guerrero, Smith \& Luk, 2016; Luk \& Bialystok, 2013). The questionnaire addressed frequency of language use and environment in a range of home and community settings. Participants reported on a sliding scale the proportion of Spanish or English used in various settings (e.g. home, university, work), interlocutors (e.g. family, friends, co-workers, clients/customers) and activities (e.g. talking, reading, writing, watching TV). It also asked participants to report their perceived ability level in 
English and Spanish for reading, writing, speaking, and listening. The internal consistency of the modified LSBQ, as measured using Cronbach's alpha against the responses of the main sample, was high at .723.

Reading Attitudes Questionnaire. Participants also completed an experimenterdesigned questionnaire with questions and agreement statements regarding motivations and attitudes toward reading in Spanish and English (e.g., I am a person who enjoys reading in English/Spanish in general; Reading for pleasure in English/Spanish helps me to relax; Reading for pleasure in English/Spanish helps me to become better informed about current affairs; Reading for pleasure in English/Spanish helps me learn more; Reading for pleasure in English/Spanish helps me achieve higher grades; Reading in English/Spanish for my university course helps me learn more; Reading in English/Spanish for my university course helps me to achieve higher grades.). Because attitudes and motivation are heavily theoretically interlinked, the questionnaire derives motivational orientations from attitudes towards reading in the respective languages, vis a vis Gardner’s (2004) Attitude/Motivation Test Battery. Learners selected an answer from a scale of 1 , "this is not at all true about me," to 5 , "this is very true about me." A separate statement was presented for Spanish and English, (e.g., I am a person who enjoys reading in English for pleasure, I am a person who enjoys reading in Spanish for pleasure.). The questionnaire was piloted with four bilingual university students to ensure clarity of questions and format. The internal consistency of the attitudes scale, as measured using Cronbach's alpha against the responses of the main sample, was high at .812 . 


\section{Results}

Participant performance on the assessment battery is presented in Table 1.

Overall, results were normally distributed, with performance means falling around 50th percentile (10) for EF tasks and slightly below 50th percentile for the WAIS (10) and WAIT (100).

Table 1

Task Performance Means

D-KEFS Trail Making (scores scaled at 10)

\begin{tabular}{lcc}
\hline Visual scanning & 11.42 & 1.72 \\
Number sequencing & 10.76 & 2.12 \\
Letter sequencing & 10.36 & 2.46 \\
Number \& letter switching & 9.84 & 2.09 \\
Combined switching & 11.12 & 2.38 \\
Motor & 9.84 & 2.67 \\
\hline D-KEFS Colour-Word Inhibition (scores scaled at 10$)$ & 2.7 \\
\hline Colour naming & 9.4 & 2.3 \\
Colour reading & 10.52 & 2.48 \\
\hline Inhibition & 10.44 & 10.4 \\
\hline
\end{tabular}

WAIS IV (scores scaled at 10) 


\begin{tabular}{lcc}
\hline Working Memory & 7.92 & 2.35 \\
Matrix Reasoning & 8.32 & 2.26 \\
\hline & WIAT III (score scaled at 100) & \\
\hline Reading Comprehension & 92.58 & 7.94 \\
\hline
\end{tabular}

Results from the modified LSBQ and reading attitudes questionnaire revealed that participants live in a highly varied bilingual environment, with schooling mostly in English, and home and work environments mixed in Spanish and English. See Figures 1 and 2 and Tables 2, 3, and 4. Correlational relationships between measures are presented in Tables 5, 6, 7, 8, 9, and 10 . 




Table 2

\begin{tabular}{lcc}
\hline Language Environment (\% in English presented) & $M$ & $S D$ \\
\hline Home & & \\
\hline Speaking & 45.4 & 29.1 \\
Listening & 40.2 & 29.9 \\
Reading & 74.3 & 28.25
\end{tabular}


Writing

Listening to music

Listening to radio

Watching TV

School

School
75.5

55.4

55.5

70.6

22.23

\begin{tabular}{|c|c|c|}
\hline Speaking & 90.4 & 14.4 \\
\hline Listening & 92.6 & 11.6 \\
\hline Reading & 97.3 & 7.83 \\
\hline Writing & 97 & 10.2 \\
\hline \multicolumn{3}{|c|}{ Work } \\
\hline Speaking to co-workers & 76.88 & 24.79 \\
\hline Speaking to clients/customers & 71.35 & 26.37 \\
\hline Listening to co-workers & 74.89 & 27.89 \\
\hline Listening to clients/customers & 73.85 & 28.36 \\
\hline Reading & 87.6 & 19.7 \\
\hline Writing & 86.15 & 23.16 \\
\hline
\end{tabular}

Table 3

Self-reported proficiency (on a scale from 0-100 "native or native-like”)

$M \quad S D$




\begin{tabular}{lcc}
\hline Speaking & 88.36 & 13.05 \\
Listening/Understanding & 94.18 & 6.88 \\
Reading & 82.65 & 15.38 \\
Writing & 72.65 & 23.58 \\
\hline English & & \\
\hline Speaking & & 6.28 \\
Listening/Understanding & 97.04 & 3.93 \\
Reading & 98.06 & 4.9 \\
Writing & 97.35 & 5.9 \\
\hline
\end{tabular}

Table 4

\begin{tabular}{|c|c|c|}
\hline Self-reported reading behaviour in English/Spanish & M & SD \\
\hline \% of overall reading done in English & 81.18 & 18.19 \\
\hline \% of reading for University done in English & 95.38 & 11.89 \\
\hline \% of reading for pleasure, including magazines, done in English & 84.62 & 17.71 \\
\hline $\begin{array}{l}\text { \% of reading online, including social media, social media apps, } \\
\text { websites, blogs, done in English }\end{array}$ & 84.08 & 16.75 \\
\hline \% of reading texts/emails/sms/messaging apps done in English & 74.23 & 17.53 \\
\hline $\begin{array}{l}\% \text { of reading posters, timetables menus, schedules done in } \\
\text { English }\end{array}$ & 84.05 & 14.97 \\
\hline
\end{tabular}




\section{Figure 2: Reading Language Environment}

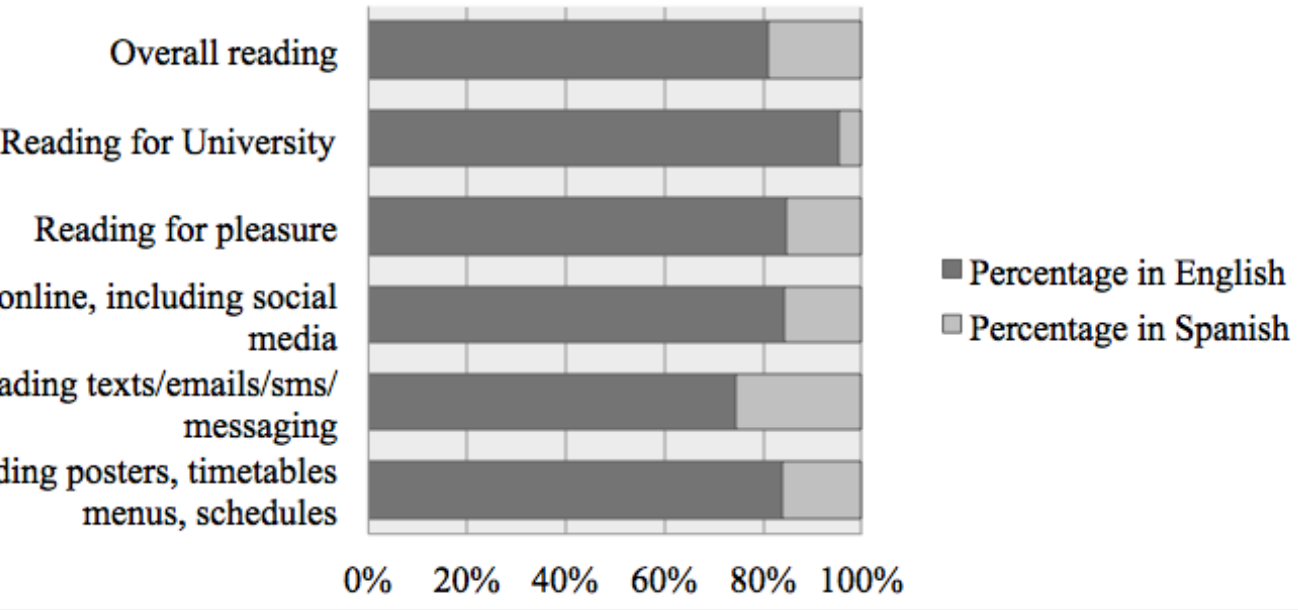

Table 5

Standardized assessment battery (D-KEFS, WAIS, WIAT): Correlations

\begin{tabular}{|c|c|c|c|c|c|c|c|c|c|c|c|c|c|}
\hline Variables & 1 & 2 & 3 & 4 & 5 & 6 & 7 & 8 & 9 & 10 & 11 & 12 & 13 \\
\hline $\begin{array}{l}\text { 1.D-KEFS Trails } \\
\text { Visual Scanning }\end{array}$ & & & & & & & & & & & & & \\
\hline $\begin{array}{l}\text { 2.D-KEFS Trails } \\
\text { Number }\end{array}$ & & & & & & & & & & & & & \\
\hline Sequencing & $.325 *$ & & & & & & & & & & & & \\
\hline $\begin{array}{l}\text { 3.D-KEFS Trails } \\
\text { Letter Sequencing }\end{array}$ & $.335 *$ & $.508^{* *}$ & & & & & & & & & & & \\
\hline $\begin{array}{l}\text { 4.D-KEFS Trails } \\
\text { Number Letter }\end{array}$ & & & & & & & & & & & & & \\
\hline Switching & $.336 *$ & $.411^{* *}$ & $.361^{*}$ & & & & & & & & & & \\
\hline $\begin{array}{l}\text { 5.D-KEFS Trails } \\
\text { Motor }\end{array}$ & $.381 * *$ & .22 & $\begin{array}{c}.378^{* *} \\
.\end{array}$ & .214 & & & & & & & & & \\
\hline $\begin{array}{l}\text { 6.D-KEFS } \\
\text { Combined Number } \\
\text { Letter Switching }\end{array}$ & $.362 *$ & $.867 * *$ & $.862 * *$ & $.445 * *$ & $.339 *$ & & & & & & & & \\
\hline $\begin{array}{l}\text { 7.D-KEFS Color } \\
\text { Naming }\end{array}$ & .174 & $.419 * *$ & .211 & .104 & .238 & $.362^{*}$ & & & & & & & \\
\hline $\begin{array}{l}\text { 8.D-KEFS Color } \\
\text { Reading }\end{array}$ & .27 & .214 & .186 & .046 & .204 & .226 & $.511^{* *}$ & & & & & & \\
\hline $\begin{array}{l}\text { 9.D-KEFS Color } \\
\text { Inhibition }\end{array}$ & $.292 *$ & $.405^{*}$ & $.328 *$ & $.434^{* *}$ & $.388^{*}$ & $.415 * *$ & $.379 * *$ & $.282 *$ & & & & & \\
\hline $\begin{array}{l}\text { 10. D-KEFS Color } \\
\text { Inhibition } \\
\text { Switching }\end{array}$ & $.333^{*}$ & $.28 *$ & .278 & $.315^{*}$ & $.3^{*}$ & $.293 * *$ & $.568 * *$ & $.5 * *$ & $.58^{* *}$ & & & & \\
\hline $\begin{array}{l}\text { 11.WAIS Matrix } \\
\text { Reasoning }\end{array}$ & .122 & -.001 & .118 & .178 & $.286^{*}$ & .079 & -.042 & -.161 & .255 & -.122 & & & \\
\hline $\begin{array}{l}\text { 12.WAIS Working } \\
\text { Memory }\end{array}$ & .059 & .139 & .248 & $.297 *$ & .782 & .223 & $.323 *$ & .256 & $.402 * *$ & .239 & $.319 *$ & & \\
\hline
\end{tabular}


13. WIAT Reading

Comprehension

$\begin{array}{lllllllllllll}.303 * & .051 & .143 & -.023 & .368 * * & .123 & -.023 & -.023 & .204 & .03 & .302 * & .045\end{array}$

${ }^{*} \mathrm{p}<.05 . * * \mathrm{p}<.01 . * * * \mathrm{p}<.001$.

Table 6

LSBQ Self-reported Language Proficiency and Reading Comprehension: Correlations

\begin{tabular}{|c|c|c|c|c|c|c|c|c|c|}
\hline Variables & 1 & 2 & 3 & 4 & 5 & 6 & 7 & 8 & 9 \\
\hline $\begin{array}{l}\text { 1. Spanish } \\
\text { Speaking }\end{array}$ & & & & & & & & & \\
\hline $\begin{array}{l}\text { 2. Spanish } \\
\text { Listening }\end{array}$ & $.479 * *$ & & & & & & & & \\
\hline 3.Spanish Reading & $.326^{*}$ & $.425 * *$ & & & & & & & \\
\hline 4.Spanish Writing & $.578 * *$ & $.3^{*}$ & $.807 * *$ & & & & & & \\
\hline $\begin{array}{l}\text { 5. English } \\
\text { Speaking }\end{array}$ & $.302 *$ & $.449 * *$ & .266 & .047 & & & & & \\
\hline $\begin{array}{l}\text { 6. English } \\
\text { Listening }\end{array}$ & .150 & $.345 * *$ & .121 & -.118 & $.818 * *$ & & & & \\
\hline 7. English Reading & .191 & $.382 * *$ & .164 & -.037 & $.838 * *$ & $.809 * *$ & & & \\
\hline 8. English Writing & .076 & $.295 *$ & .132 & -.059 & $.666 * *$ & $.694^{* *}$ & $.822 * *$ & & \\
\hline $\begin{array}{l}\text { 9. WIAT Reading } \\
\text { Comprehension }\end{array}$ & .275 & .169 & -.053 & .023 & $.326^{*}$ & $.434^{* *}$ & $.447 * *$ & $.337 *$ & \\
\hline
\end{tabular}

\section{Table 7}

LSBQ Home Language Use (\% English) and Reading Comprehension: Correlations

\begin{tabular}{lllllllll}
\hline Variables & 1 & 2 & 3 & 4 & 5 & 6 & 7 & 8 \\
\hline
\end{tabular}

1. Speaking 


\begin{tabular}{|c|c|c|c|c|c|c|c|}
\hline 2. Listening & $.777^{*}$ & & & & & & \\
\hline 3. Reading & $.55^{* *}$ & $.47 * *$ & & & & & \\
\hline 4. Writing & $.459 * *$ & $.453^{* *}$ & $.802 * *$ & & & & \\
\hline 5. Watching TV & .082 & .097 & $.313^{*}$ & $.297^{*}$ & & & \\
\hline $\begin{array}{l}6 \text {. Listening to } \\
\text { radio }\end{array}$ & .134 & .122 & $.346^{*}$ & .208 & $.698 * *$ & & \\
\hline $\begin{array}{l}\text { 7. Listening to } \\
\text { music }\end{array}$ & .140 & .016 & $.298^{*}$ & .158 & $.576^{* *}$ & $.874 * *$ & \\
\hline $\begin{array}{l}\text { 8. WIAT } \\
\text { Reading } \\
\text { Comprehension }\end{array}$ & -.078 & -.143 & -.214 & -.112 & -.1 & 0.008 & -.084 \\
\hline
\end{tabular}

\section{Table 8}

LSBQ School Language Use (\% English) and Reading Comprehension: Correlations

\begin{tabular}{|c|c|c|c|c|c|}
\hline Variables & 1 & 2 & 3 & 4 & 5 \\
\hline \multicolumn{6}{|l|}{ 1. Speaking } \\
\hline 2. Listening & $.685^{* *}$ & & & & \\
\hline 3. Reading & $.466 * *$ & $.617 * *$ & & & \\
\hline 4. Writing & $.535 * *$ & $.7 * *$ & $1^{* *}$ & & \\
\hline $\begin{array}{l}\text { 5. WIAT Reading } \\
\text { Comprehension }\end{array}$ & .087 & .082 & -.104 & -.289 & \\
\hline
\end{tabular}

\section{Table 9}

LSBQ Work Language Use (\% English) and Reading Comprehension: Correlations

\begin{tabular}{llllllll}
\hline Variables & 1 & 2 & 3 & 4 & 5 & 6 & 7 \\
\hline
\end{tabular}

1. Coworker 
Speaking

2. Client Speaking

$.699 * *$

3. Coworker

Listening

$.81^{* *} \quad .608 * *$

4.Client Listening

$.742 * * \quad .883^{* *} \quad .693^{* *}$

5. Reading

$\begin{array}{llll}.599 * * & .603^{* *} & .555^{* *} & .576^{* *}\end{array}$

6. Writing



7. WIAT Reading

Comprehension

$-.159$

$-.307^{*}$

$-.146$

$-.350 *$

$-.117$

$-.049$

${ }^{*} \mathrm{p}<.05 .{ }^{* *} \mathrm{p}<.01 .{ }^{* * *} \mathrm{p}<.001$.

\section{Table 10}

Reading Attitudes Questionnaire and Reading Comprehension: Correlations

\begin{tabular}{|c|c|c|c|c|c|c|c|c|c|c|c|}
\hline Variables & 1 & 2 & 3 & 4 & 5 & 6 & 7 & 8 & 9 & 10 & 11 \\
\hline \multicolumn{12}{|l|}{$\begin{array}{l}\text { 1. I am a person who } \\
\text { enjoys reading in } \\
\text { Spanish in general. }\end{array}$} \\
\hline $\begin{array}{l}\text { 2. Reading for pleasure } \\
\text { in Spanish helps me to } \\
\text { relax. }\end{array}$ & $.736 * *$ & & & & & & & & & & \\
\hline $\begin{array}{l}\text { 3. Reading for pleasure } \\
\text { in Spanish helps me to } \\
\text { become better informed } \\
\text { about current affairs. }\end{array}$ & $.647 * *$ & $.782 * *$ & & & & & & & & & \\
\hline $\begin{array}{l}\text { 4. Reading in Spanish } \\
\text { for my university course } \\
\text { helps me to learn more. }\end{array}$ & $.434 * *$ & $.506^{* *}$ & $.518 * *$ & & & & & & & & \\
\hline $\begin{array}{l}\text { 5. Reading in Spanish } \\
\text { for my university course } \\
\text { helps me to achieve } \\
\text { higher grades. }\end{array}$ & $.461^{* *}$ & $.536 * *$ & $.516^{* *}$ & $.960 * *$ & & & & & & & \\
\hline $\begin{array}{l}\text { 6. I am a person who } \\
\text { enjoys reading in } \\
\text { English in general. }\end{array}$ & -.053 & -.008 & -.082 & -.01 & -.075 & & & & & & \\
\hline $\begin{array}{l}\text { 7. Reading for pleasure } \\
\text { in English helps me to } \\
\text { relax. }\end{array}$ & -.002 & 0.144 & -.001 & .173 & .078 & $.840 * *$ & & & & & \\
\hline
\end{tabular}


8. Reading for pleasure

in English helps me to

become better informed

about current affairs.

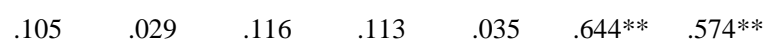

9. Reading in English

for my university course

helps me to learn more.

10. Reading in English

for my university course

helps me to achieve

higher grades.

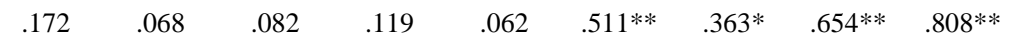

11. WIAT Reading

Comprehension

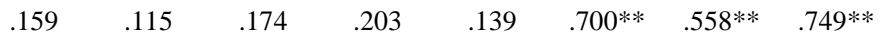

${ }^{*} \mathrm{p}<.05 .{ }^{* *} \mathrm{p}<.01 .{ }^{* * *} \mathrm{p}<.001$.

\section{RQ 1: Which variables best account for variance in reading comprehension scores}

among Spanish-English bilingual undergraduates?

A multiple regression model revealed that matrix reasoning score, digit span

score, and self-reported English reading comprehension, and composite score of positive attitudes toward reading in Spanish and English accounted for the most variance in reading comprehension scores, $F(\mathrm{DF} 1, \mathrm{DF} 2)=2.50, p=.03, R^{2}=.39$.

Building hierarchically on this model, agreement with statements regarding reading assigned course material to achieve higher grades made a unique contribution to variance in reading comprehension outcomes. Greater agreement with the statement "Reading in English for my university course helps me achieve higher grades" made a unique significant contribution to variance, when controlling for matrix reasoning score, digit span score, and self-reported English reading comprehension $F(4,31)=3.33, p<$ $.05, R^{2} \Delta=.08$. Greater agreement with the statement "Reading in Spanish for university course helps me achieve higher grades" also made a unique significant contribution to variance, when controlling for matrix reasoning score, digit span score, and self-assessed English reading ability $F(4,31)=3.04, p<.05, R^{2} \Delta=.06$. 
Self-reported amount of time spent reading for pleasure or school made no significant, unique contribution to reading comprehension scores, after controlling for matrix reasoning score, digit span score, and self-reported English reading comprehension. Neither did agreement with statements regarding reading for pleasure (e.g., "I am a person who enjoys reading in Spanish/English in general," "Reading for

pleasure in Spanish/English helps me to relax," "Reading for pleasure in Spanish/English helps me to become better informed about current affairs," "Reading in Spanish/English for pleasure helps me achieve higher grades”) or reading for university courses to learn more, independent of grades (e.g., "Reading in Spanish/English for my university course helps me to learn more").

\section{RQ 2: Do any environmental factors uniquely contribute to variance in reading comprehension scores among Spanish-English bilingual undergraduates?}

A composite variable of client/customer communication, using reported language use for speaking with and listening to clients/customers made a unique significant contribution to variance, when controlling for matrix reasoning score and digit span score, $F(3,44)=3.13, p<.05, R^{2} \Delta=.08$. A lower amount of English being used when communicating with clientele was associated with higher scores for reading comprehension. A combined model of matrix reasoning score, digit span score, and clientele communication accounted for $17.6 \%$ of variance in reading scores, $F(3,44)=$ $3.13, p=.04$. 


\section{RQ 3: What is the attitudinal and behavioural reading profile of Spanish-English bilingual undergraduates?}

Enjoyment of reading in English in general correlated positively with pleasure reading in English for relaxation $(r=.84, p=.00)$, pleasure reading in English to be informed about current affairs $(r=.644, p=.000)$, reading in English for your university course in order to learn more $(r=.700, p=.000)$, and reading in English for your university course to achieve higher grades $(r=.511, p=.001)$. Enjoyment of reading in Spanish was positively correlated with the same variables referring to Spanish ( $p$ s $\leq$ .001). In terms of reading attitudes and language environment, enjoyment of reading in Spanish in general was negatively correlated with using English in the home environment for both speaking $(r=-.401, p=.014)$ and reading $(r=-.446, p=.006)$ and with use of English for reading in the school environment $(r=-.354, p=.031)$, and was positively correlated with listening to co-workers in English in the work environment $(r=.357, p=$ .032). Furthermore, positive attitude toward reading in Spanish for relaxation was positively correlated with listening $(r=.405, p=.014)$ and speaking $(r=.360, p=.034)$ to co-workers in English. Enjoyment of reading in English did not correlate significantly with any of the language environment variables. With regard to proficiency, enjoyment of reading in English showed a positive relationship to self-reported proficiency in English listening $(r=.472, p=.004)$, reading $(r=.640, p=.000)$ and writing $(r=.568, p=.000)$. Enjoyment of reading in Spanish in general was not significantly correlated with any of the self-reported proficiency scales.

Regarding reading behaviours, proportion of time spent reading in English was significantly positively correlated with proportion of reading in English for participants’ 
university course $(r=.330, p=.04)$ and reading Internet sources in English $(r=.414, p=$ .009), and negatively correlated with reading for pleasure in Spanish to become better informed about current affairs $(r=-.374, p=.022)$. Proportion of time spent reading in Spanish correlated with the same variables referring to Spanish ( $p s \leq .04)$. Proportion of reading in English for your university course was further positively correlated with reading books/magazines in English for pleasure $(r=.429, p=.006)$ and reading Internet sources in English ( $r=.375, p=.019)$ (with the same significant positive correlations for these variables in Spanish, $p s \leq .02$ ). Likewise, reading emails/texts/instant messages in English correlated positively with reading Internet web sources in English $(r=.437, p=$ .005) and was similarly negatively correlated to Spanish.

Regarding attitudes and reading behaviours, the attitude that reading in English for your university course helps you to learn more was significantly positively correlated with reading posters/schedules/menus in English $(r=.379, p=.017)$ and similarly negatively correlated to this reading behaviour in Spanish. Attitude towards reading for pleasure in English to become better informed about current affairs was positively correlated with proportion of reading books/magazines for pleasure in English ( $r=.361$, $p=.028)$ and negatively to the same behaviour in Spanish $(p=<.03)$.

Thus, the findings related to RQ3 indicate that: (1) enjoyment of reading in both languages is related to positive attitudes about the value of reading for relaxation, for general information, for academic development, and for academic attainment; (2) enjoyment of reading in Spanish bears a negative relationship to using English for reading and speaking in the home environment, whereas enjoyment of reading in Spanish bears a positive relationship to using English to listen to co-workers in the work 
environment and finding reading in Spanish relaxing is linked to greater interaction in English with co-workers; (3) enjoyment of reading in English is linked to self-efficacy beliefs with regard to English reading, writing and listening proficiency; (4) reading behaviours in both languages derive from the need for information, for pleasure, for communication and for academic development; and (5) there is a relationship between reading-related attitudes and reading behaviours among Spanish-English bilingual undergraduates with regard to reading for general information and for academic development.

\section{Discussion}

Spanish-English bilingual university students show differential reading comprehension outcomes, which are significantly predicted by differences in attitudes toward reading, and environmental language usage. Reading comprehension shows strong relationship to extrinsic and/or instrumental motivation, comparable to previous findings among second language learners in other settings. Therefore, in relation to the research questions, the variables that best account for variance in reading comprehension among Spanish-English college students are environmental usage (workplace communication with clients/customers), self-reported proficiency (English reading), and attitudes/motivation (extrinsically motivated reading in either Spanish or English).

The observed significant contribution of agreement with statements regarding the value of reading for academic success provides reading-specific evidence supporting the importance of utility value, defined as the perceived value of a task to achieving one’s goals (c.f. Eccles et al.’s (1983) expectancy-value model), as a component strongly predictive of achievement. Thus, our study strengthens and supports evidence from non- 
reading-specific research (e.g. Steinmayr \& Spinath, 2010; Hulleman, Durik, Schweigert \& Harackiewicz, 2008) that the utility value is the component of the expectancy-value model most strongly predictive of general achievement. In this model, the value of reading in English or Spanish for participants may be tied to their perception of its correlation with higher grades. Participants that believe this link to be stronger may engage in more reading, resulting in higher reading performance. This relationship has also been demonstrated by El-Khechen, Ferdinand, Steinmayr \& McElvany (2016), who found that utility value placed on German by German-Turkish bilinguals predicted German reading competency. As such, the contribution of this study to theoretical frameworks is the extension of these frameworks to reading specific research.

However, in contrast to El-Khechen and colleagues’ 2016 findings, in which German reading comprehension was predicted negatively by Turkish utility value, we found that Spanish utility did positively predict English reading outcomes. This might be attributed to students' ability to translate between the two, or the possible availability of material in Spanish to support courses taught in English.

The connection between reading comprehension in English and the perception that reading in Spanish helps with English course outcomes may be related to the similarity between the two languages, including cognates and alphabetic system; these similarities are not as strong in the case of German and Turkish. Quiroz (2014) found that "good" Spanish-English bilingual young adult readers use more cognate-based strategies for reading comprehension, while "average” readers rely on more contextbased strategies. As such, agreement with the statement "Reading in Spanish for my university course helps me achieve higher grades” may be linked to cognate recognition, 
metalinguistic knowledge of cognates, or use of cognate strategies. Further, students who are stronger readers overall in both languages may have higher recognition of the importance of reading in both. Causality is therefore unclear, since stronger readers may be better able to access benefit from reading for academic success overall and therefore agree more strongly with the grade-based statements. These stronger readers may derive more benefit from reading than students with minimal comprehension of their academic reading, who consequently are less motivated to read and see less benefit from reading overall.

Our findings indicate that environmental language use also contributes to differences between learners, echoing previous research that has found environmental language differences to contribute to diversity within adult bilingual populations (see Kroll \& Bialystok, 2013 for a review). In our findings, increased use of Spanish with clients/customers in a work setting shows a relationship with English reading, but use with co-workers did not. This may be related to language skill and cognitive effort needed to regularly negotiate, problem-solve, and perform politeness routines in Spanish and English, sometimes even unpredictably, as the customer may determine the language of use. This could result in a dynamic language switching environment supporting greater vocabulary development in both languages and positively impact reading development, especially if workplace activities involve translating between the two languages. It is also possible that the attitudinal impact of Spanish being a job skill supports increased motivation for reading in Spanish and the added social value of Spanish in the workplace results in greater self-efficacy or higher positive attitudes toward language and reading overall. Psycholinguistic models such as Kroll's Revised 
Hierarchical Model (Kroll \& Tokowicz, 2005) and the Bilingual Interactive Activation Model (Dijkstra \& van Heuven, 2002) posit that increased proficiency in a language results in increased activation of that language; specifically within the context of lexical retrieval and production. A further possibility is that increased use of Spanish in the workplace for problem-solving client interactions results in greater Spanish activation, supporting development in Spanish and potentially supporting advancement in both languages.

Our finding that individual and environmental factors (such as workplace language use) is associated with variation in reading outcomes supports our assertion that these students are not homogeneous and are still developing, and has implications for both future research and institutions of higher education. While students may have met university reading entry thresholds, differences at this level likely have crucial implications for university outcomes and retention rates for US Latino students, and thus demand further rigorous study. While there are many factors involved, we identify these potential key elements: a relatively monolingual English environment (especially for young adults used to bilingual communities), the use of curriculum developed for monolinguals, and a lack of insight into bilingual students' language development at this level. If further investigation reveals that positive reading attitudes support university reading skills, active instructional emphasis could be placed on further developing positive attitudes during earlier schooling, in particular, attitudes toward the functionality of reading in both English and Spanish. Directionality of relationships between environmental Spanish use and English reading outcomes could also be examined. It may be that learners who are more advanced and skilled language users in general are 
better able to use Spanish in a dynamic work performance setting, as well as being more skilled readers. However, if environmental Spanish language use, for example regular Spanish use in challenging work interactions, supports development in English as well, opportunities for this type of rich language use could be also be supported in schooling.

Exploring the directionality of relationships between language environment, attitudes, and English reading comprehension among bilingual young adults will likely be a fruitful avenue of future research. The current study provides a launching point for further exploration, but also has limitations. Though generalizations are hindered by the relative homogeneity of this sample, which is evidenced by the similar geographic, ethnic/cultural, and socio-economic backgrounds of participants, this homogeneity also allows differences between bilingual individuals to be clearly revealed with fewer mitigating factors. Further study should examine if these findings are specific to this population in this geographic region. The single time point nature of this data does not allow directionality - future research may wish to incorporate more than one time point to allow insight into how these relationships may change. The current study can only offer insights into current differences between students and cannot capture or describe changes that may be occurring; a cross-lag design might deepen our understanding of how these relationships might develop.

Funding: This research received no specific grant from any funding agency in the public, commercial, or not-for-profit sectors. This research was generously funded by a Faculty Support Grant to the first author from California State University East Bay, and grants from the California State University East Bay Center for Student Research. 


\section{References}

Afflerbach, P., Pearson, D., \& Paris, S. (2008). Clarifying differences between reading skills and reading strategies. The Reading Teacher, 61(5), 364-373. doi:10.1598/RT.61.5.1

Akhtar, N., \& Menjivar, J.A. (2012). Cognitive and linguistic correlates of early exposure to more than one language. In J. B. Benson (Ed.), Advances in child development and behaviour, Vol. 42 (pp. 41-78). Burlington: Academic Press.

Anastasiou, D., \& Griva, E. (2009). Awareness of reading strategy use and reading comprehension among poor and good readers. Elementary Education Online, 8(2), 283-297.

Anderson, E. C., Vanderhoff, A. M., \& Donovick, P. J. (2013). A manifestation of the bilingual disadvantage in college-level writing. International Journal of Language Studies, 7(1), 135-150.

Appel, R. \& Muysken, P. (2005). Language contact and bilingualism. Amsterdam, Netherlands: Amsterdam University Press.

Barac, R., Bialystok, E., Castro, D.C., \& Sanchez, M. (2014). The cognitive development of young dual language learners: A critical review. Early Childhood Research Quarterly, 29(4), 699-714. doi:10.1016/j.ecresq.2014.02.003

Bialystok, E., Craik, F.I.M., \& Luk, G. (2008a). Cognitive control and lexical access in younger and older bilinguals. Journal of Experimental Psychology: Learning, Memory, and Cognition, 34(4), 859-873. doi:10.1037/0278-7393.34.4.859 
Bialystok, E., Craik, F.I.M., \& Luk, G. (2008b). Lexical access in bilinguals: Effects of vocabulary size and executive control. Journal of Neurolinguistics, 21(6), 522538. doi:10.1016/j.jneuroling.2007.07.001

Bialystok, E., Luk, G., Peets, K.F., \& Yang, S. (2010). Receptive vocabulary differences in monolingual and bilingual children. Bilingualism: Language and Cognition, 13(4), 525-531. doi:10.1017/S1366728909990423

Bialystok, E., Poarch, G., Luo, L., \& Craik, F. I. (2014). Effects of bilingualism and aging on executive function and working memory. Psychology and aging, 29(3), 696.

Deci, E. L. \& Ryan, R. M. (1985). Intrinsic motivation and self-determination in human behaviour. New York: Plenum.

Deci, E. L. \& Ryan, R. M. (1985). The general causality orientations scale: Selfdetermination in personality. Journal of Research in Personality, 19(2), 109-134. doi:10.1016/0092-6566(85)90023-6

Dewey, D. (2008). Japanese Vocabulary Acquisition by Learners in Three Contexts. Frontiers: The Interdisciplinary Journal of Study Abroad, 15, 127-148. Retrieved from http://frontiersjournal.org/wp-content/uploads/2015/09/DEWEYFrontiersXV-JapaneseVocabularyAcquisitionbyLearnersinThreeContexts.pdf

Dhanapala, K. V. (2006). Intrinsic motivation, extrinsic motivation and L2 reading comprehension of university learners in Japan and Sri Lanka. Proceedings of the JACET Summer Seminar, 6, 39-43. 
Dhanapala, K. V. \& Hirakawa, Y. (2016). L2 reading motivation among Sri Lankan university students. Reading Psychology, 37(2), 202-229. doi:10.1080/02702711.2015.1025163

Dijkstra, T. \& Van Heuven, W.J.B. (2002). The architecture of the bilingual word recognition system: from identification to decision Bilingualism. Language and Cognition. 5(3), 175-197. doi:10.1017/S1366728902003012

Dijkstra, T. \& van Heuven, W.J.B., (2002). Modeling bilingual word recognition: Past, present and future Bilingualism. Language and Cognition. 5(3), 219-224. doi:10.1017/S1366728902283017

Dussias, P. E., \& Sagarra, N. (2007). The effect of exposure on syntactic parsing in Spanish-English bilinguals. Bilingualism: Language and Cognition, 10(01), 101116.

Eccles, J. S., Adler, T. F., Futterman, R., Goff, S. B., Kaczala, C. M., Meece, J. L., \& Midgley, C. (1983). Expectancies, values, and academic behaviours. In J. T. Spence (Ed.), Achievement and achievement motivation (pp. 75-146). San Francisco, CA: W. H. Freeman.

El-Khechen, W., Ferdinand, H., Steinmayr, R., \& McElvany, N. (2016). Languagerelated values, reading amount and reading comprehension in students with migration background. British Journal of Educational Psychology, 86(2), 256277. doi:10.1111/bjep.12102 
Engle, R. W., Cantor, J., \& Carullo, J. J. (1992). Individual differences in working memory and comprehension: a test of four hypotheses. Journal of Experimental Psychology: Learning, Memory, and Cognition, 18(5), 972.

Fishman, J. A., \& Cooper, R. L. (1969). Alternative measures of bilingualism. Journal of Verbal Learning and Verbal Behavior, 8(2), 276-282

Freed, B. F., Segalowitz, N., \& Dewey, D. (2004). Context of learning and second language fluency in French: Comparing regular classroom, study abroad, and intensive domestic immersion programs. Studies in Second Language Acquisition, 26(2), 275-301. doi:10.1017/S0272263104262064

Friesen, D. C., Latman, V., Calvo, A., \& Bialystok, E. (2015). Attention during visual search: The benefit of bilingualism. International Journal of Bilingualism, 19(6), 693-702.

Gardner, R.C. (1979). Social psychological aspects of second language acquisition. In Giles, H. \& St. Clair, R. (eds.) Language and social psychology. (pp. 193-220). Oxford: Basil Blackwell.

Gardner, R. C., Ginsberg, R. E., \& Smythe, P. C. (1976). Attitude and motivation in second-language learning: Course related changes. Canadian Modern Language Review, 32, 243-266.

Gardner, R. C. \& Lambert, W. E. (1972). Attitudes and motivation in second language learning. Rowley, MA: Newbury House. 
Gardner, R. C., Smythe, P. C., Clément, R., \& Gliksman, L. (1976). Second language learning: A social psychological perspective. Canadian Modern Language Review, 32,198-213.

Grabe, W. (2009). Reading in a second language: Moving from theory to practice. New York, NY: Cambridge University Press.

Hayashi, K. (1999). Reading strategies and extensive reading in EFL classes. RELC Journal, 30(2), 114-132. doi:10.1177/003368829903000207

Hernández, T. A. (2010). Promoting speaking proficiency through motivation and interaction: The study abroad and classroom learning contexts. Foreign Language Annals, 43(4):650-670. doi:10.1111/j.1944-9720.2010.01107.x

Hulleman, C. S., Durik, A. M., Schweigert, S., \& Harackiewicz, J. M. (2008). Task values, achievement goals, and interest: An integrative analysis. Journal of Educational Psychology, 100(2), 398-416. doi:10.1037/0022-0663.100.2.398

Kim, K. J. (2011). Reading motivation in two languages: An examination of EFL college students in Korea. Reading and Writing, 24(8), 861-881. doi:10.1007/s11145010-9229-z

Kroll, J. F., \& Bialystok, E. (2013). Understanding the consequences of bilingualism for language processing and cognition. Journal of Cognitive Psychology, 25(5), 497514. doi: 10.1080/20445911.2013.799170

Kroll, J. F., Dussias, P. E., Bogulski, C. A., \& Valdes Kroff, J. R. (2012). 7 Juggling Two Languages in One Mind: What Bilinguals Tell Us About Language Processing 
and its Consequences for Cognition. Psychology of Learning and MotivationAdvances in Research and Theory, 56, 229.

Kroll, J.F. \& Tokowicz, N. (2005). Models of bilingual representation and processing. In J.F. Kroll \& A.M.B. De Groot. (Eds). Handbook of Bilingualism: Psycholinguistic Approaches (pp. 531-553). New York, NY; Oxford University Press.

Lau, K. (2006). Reading strategy use between Chinese good and poor readers: a thinkaloud study. Journal of Research in Reading, 29(4), 383-399. doi:10.1111/j.14679817.2006.00302.x

Leon Guerrero, S., Smith, S., \& Luk, G. (2016). Home language usage and cognitive control in bilingual preschoolers. In J. Schwieter (Ed.) The cognitive control and consequences of Multilingualism: Bilingual Processing and Acquisition. Philadelphia, PA: John Benjamins.

Lin, D., Wong, K. K., \& McBride-Chang, C. (2012). Reading motivation and reading comprehension in Chinese and English among bilingual students. Reading and Writing: An Interdisciplinary Journal, 25(3), 717-738. doi:10.1007/s11145-011$9297-8$

Luk, G. \& Bialystok, E. (2013). Bilingualism is not a categorical variable: Interaction between language proficiency and usage. Journal of Cognitive Psychology, 25(5), 605-621. doi:10.1080/20445911.2013.795574 
Martinsen, R. (2011). Predicting changes in cultural sensitivity among students of Spanish during short-term study abroad. Hispania, 94(1), 121-141. doi:0.1353/hpn.2011.0002

Masgoret, A. M. \& Gardner, R. C. (2003). Attitudes, motivation, and second language learning: A meta-analysis of studies conducted by Gardner and associates. Language Learning, 53(1), 123-163. doi:10.1111/1467-9922.00212

McVay, J. C., \& Kane, M. J. (2012). Why does working memory capacity predict variation in reading comprehension? On the influence of mind wandering and executive attention. Journal of experimental psychology: general, 141(2), 302.

Mol, S. E. \& Bus, A. G. (2011). To read or not to read: A meta-analysis of print exposure from infancy to early adulthood. Psychological Bulletin, 137(2), 267-296. doi:10.1037/a0021890.

Muñoz, C. \& Llanes, À. (2014). Study Abroad and Changes in Degree of Foreign Accent in Children and Adults. The Modern Language Journal, 98(1), 432-449. doi:10.1111/j.1540-4781.2014.12059.x

Netten, A., Droop, M., \& Verhoeven, L. (2011). Predictors of reading literacy for first and second language learners. Reading and Writing: An Interdisciplinary Journal, 24(4), 413-425. doi:10.1007/s11145-010-9234-2

O.E.C.D. (2010). PISA 2009 Results: Executive Summary. Retrieved August 2, 2016 from https://www.oecd.org/pisa/pisaproducts/46619703.pdf 
Petscher, Y. (2010). Meta-analysis of the relationship between attitudes towards reading and achievement in reading. Journal of Research in Reading, 33(4), 335-355. doi:10.1111/j.1467-9817.2009.01418

Pew Research Center. (2013). National Survey of Latinos. Retrieved July 7, 2016 from http://www.pewhispanic.org/category/datasets/http://www.pewhispanic.org/categ ory/datasets/http://www.pewhispanic.org/category/datasets/

Pichette, F. (2005). Time spent on reading and reading comprehension in second language learning. The Canadian Modern Language Review / La revue canadienne des langues vivantes, 62(2), 243-262. doi:10.1353/cml.2006.0008

Quiroz, G. (2014). Reading strategies of good and average bilingual readers of Chinese and Spanish backgrounds (Published graduate thesis). Retrieved from ProQuest Dissertations \& Theses Full Text: The Humanities and Social Sciences Collection. (1570581)

Ransdell, S. (2003). The care and feeding of monolingual and bilingual university students in south Florida: Implications for assessment and training. Psychology Learning and Teaching 3(2):126-130. doi:10.2304/plat.2003.3.2.126

Sesma, H. W., Mahone, E. M., Levine, T., Eason, S. H., \& Cutting, L. E. (2009). The contribution of executive skills to reading comprehension. Child Neuropsychology, 15(3), 232-246.

Segalowitz, N., \& Freed, B. F. (2004). Context, contact and cognition in oral fluency acquisition: Learning Spanish in At Home and Study Abroad contexts. Studies in Second Language Acquisition, 26(2), 173-199. doi:10.1017/S0272263104262027 
Stanovich, K. E. (2000). Progress in understanding reading: Scientific foundations and new frontiers. New York: Guilford Press

Steinmayr, R. \& Spinath, B. (2010). Konstruktion und erste Validierung einer Skala zur Erfassung subjektiver schulischer Werte (SESSW) [Construction and initial validation of a scale for measuring subjective school values]. Diagnostica, 56(4), $195-211$.

Takase, A. (2007). Japanese high school students' motivation for extensive L2 reading. Reading in a Foreign Language, 19(1), 1-18.

Tercanlioglu, L. (2001). The nature of Turkish students' motivation for reading and its relation to their reading frequency. The Reading Matrix, 1(2). Retrieved from http://www.readingmatrix.com/archives/archives_vol1_no2.html

US Census Bureau. (2014). Percentage of 18- to 24-year-olds enrolled in degreegranting institutions, by level of institution and sex and race/ethnicity of student: 1967 through 2013. Retrieved July 7, 2016 from http://nces.ed.gov/programs/digest/d14/tables/dt14_302.60.asp?current=yeshttp:// nces.ed.gov/programs/digest/d14/tables/dt14_302.60.asp?current=yes

US Department of Education. (2014). Total fall enrollment in degree-granting postsecondary institutions, by level of enrollment, sex, attendance status, and race/ethnicity of student: Selected years, 1976 through 2013. Retrieved July 7, 2016 from http://nces.ed.gov/programs/digest/d14/tables/dt14_306.10.asp?current=yeshttp:// nces.ed.gov/programs/digest/d14/tables/dt14_306.10.asp?current=yes 
Yager, K. (1998). Learning Spanish in Mexico: The effect of informal contact and student attitudes on language gain. Hispania, 81(4): 898-913.

doi: 10.2307/345798http://dx.doi.org/10.2307/345798 